\title{
Micropropagação de framboeseira em diferentes concentrações de ferro
}

\author{
Adjustment of the iron concentration in the culture medium to raspberry micropropagation
}

\author{
Roberto Pedroso de Oliveira ${ }^{\mathrm{I}^{*}}$ Paulo Sérgio Gomes da Rocha ${ }^{\mathrm{I}}$ Vanessa Flores Gularte ${ }^{\mathrm{II}}$ \\ Walkyria Bueno ScivittaroI
}

\begin{abstract}
Objetivou-se otimizar a micropropagação das cultivares 'Heritage' e 'Batum' de framboeseira, ajustando-se a concentração de ferro do meio de cultura. Os tratamentos, avaliados durante a fase de multiplicação dos explantes, consistiram em modificações do meio MS quanto à concentração de ferro $\left(0,25,50\right.$ e $75 \mathrm{mg} \mathrm{L}^{-1}$ de $\left.\mathrm{FeSO}_{4} .7 \mathrm{H}_{2} \mathrm{O}\right)$. Foram realizados três subcultivos de 45 dias, sob condições


Utilizou-se delineamento experimental inteiramente casualizado, em um bifatorial (duas cultivares $x$ quatro doses de $\mathrm{FeSO}_{4} \cdot 7 \mathrm{H}_{2} \mathrm{O}$ ), com quatro repetições, sendo as unidades experimentais constituidas por um frasco contendo cinco explantes de $8-10 \mathrm{~mm}$ com três a quatro gemas. Independentemente da concentração de ferro do meio de cultura, a 'Heritage' apresentou maior número médio de brotos por explante $(6,9)$, proporcionando a produção de 501,1 plantas em três subcultivos, enquanto que a 'Batum' apresentou número de brotos de 6,0 e produção de 306,3 plantas. A concentração ideal de $\mathrm{FeSO}_{4} .7 \mathrm{H}_{2} \mathrm{O}$ no meio de cultura para multiplicação in vitro dos explantes foi de $43,4 m g L^{-1}$, para a 'Heritage', e de 43,1 $\mathrm{mg} \mathrm{L}^{-1}$, para a 'Batum'.
\end{abstract}

Palavras-chave: 'Batum', 'Heritage', cultura de tecidos, produção de mudas.

\begin{abstract}
The aim of this research was to optimize the micropropagation of 'Heritage' and 'Batum' raspberries, adjusting the iron concentration in the culture medium. The treatments were evaluated during the explant multiplication, using MS medium modified in $\mathrm{FeSO}_{4} .7 \mathrm{H}_{2} \mathrm{O}$ concentration (0, 25, 50 and $\left.75 \mathrm{mg} \mathrm{L}^{-1}\right)$. The experiment was carried out during
\end{abstract}

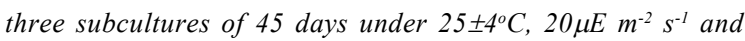
photoperiod of 16 hours. The experimental design was a factorial entirely randomized (two cultivars $x$ four $\mathrm{FeSO}_{4} .7 \mathrm{H}_{2} \mathrm{O}$ concentrations) with four replications. The experimental unit consisted of a flask with five explants $(8-10 \mathrm{~mm}$ diameter with three to four shoots). Independently of the iron concentration in the culture medium, 'Heritage' showed the highest number of shoots per explant (6.9) providing the production of 501.1 plants in three subcultures, while 'Batum' showed 6.0 shoots per explant and production of 306.3 plants. The best $\mathrm{FeSO}_{4} .7 \mathrm{H}_{2} \mathrm{O}$ concentration in culture medium for explant multiplication was $43.4 \mathrm{mg} \mathrm{L}^{-1}$ for 'Heritage' and $43.1 \mathrm{mg} \mathrm{L}^{-1}$ for 'Batum'.

Key words: 'Batum', 'Heritage', tissue culture, plant production.

A framboeseira (Rubus idaeus L.) é uma espécie do grupo das pequenas frutas. Trata-se de uma cultura de baixo custo de implantação, que demanda bastante mão-de-obra, mas que apresenta alta rentabilidade por hectare (OLIVEIRA \& NINO, 2009). No Brasil, a produção de framboesa é realizada principalmente nos Estados de São Paulo, Minas Gerais e Rio Grande do Sul, com uma área cultivada de 60ha e produção anual de 180 toneladas, sendo as cultivares 'Heritage' e 'Batum' as mais plantadas (IBGE, 2010).

A propagação da framboeseira pode ser realizada por estaquia de raízes, enraizamento de estacas e por cultura in vitro de tecidos, sendo este

'Embrapa Clima Temperado, CP 403, 96001-970, Pelotas, RS, Brasil. E-mail: roberto.pedroso@cpact.embrapa.br. *Autor para correspondência.

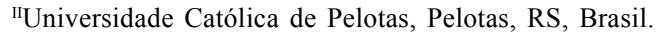


último procedimento o mais seguro para evitar contaminações por patógenos. O gênero Rubus é bastante responsivo in vitro, obtendo-se taxas de multiplicação satisfatórias, com valores variando de 3,0 a 7,9 por subcultivo de 30 a 45 dias, dependendo da cultivar e das condições de cultivo (OLIVEIRA \& NINO, 2009). No entanto, uma observação mais detalhada das plantas propagadas na Embrapa Clima Temperado indicou a existência de sintomas de clorose internerval, confirmada, após análise química, como sendo decorrente de deficiência de ferro (DECHEN \& NACHTIGALL, 2006).

$\mathrm{O}$ ferro é um micronutriente essencial para a organização dos meristemas e crescimento das brotações (HANSEN et al., 2006). Em cultura de tecidos, pode ser adicionado nas formas quelatizada ou inorgânica, sendo utilizado, no meio MS (MURASHIGE \& SKOOG, 1962), a fonte $\mathrm{FeSO}_{4} \cdot 7 \mathrm{H}_{2} \mathrm{O}$.

O objetivo deste trabalho foi otimizar a produção in vitro de mudas das cultivares Heritage e Batum de framboeseira, por meio do ajuste da concentração de ferro em meio de cultura MS.

$\mathrm{O}$ trabalho foi realizado no laboratório de Cultura de Tecidos da Embrapa Clima Temperado, em Pelotas-RS, utilizando as cultivares 'Heritage' e 'Batum'. Ponteiros foram coletados na Coleção de Pequenas Frutas da Embrapa Clima Temperado. A desinfestação foi realizada em soluções compostas por álcool etílico a $70 \%(\mathrm{v} / \mathrm{v})$ e por hipoclorito de sódio $(\mathrm{NaOCl})$ a $1 \%(\mathrm{v} / \mathrm{v})$. Em seguida, foram lavados três vezes com água destilada e autoclavada.

Trinta meristemas $( \pm 0,3 \mathrm{~mm})$ de cada cultivar foram isolados em câmara de fluxo laminar, sob lupa estereoscópica. Em seguida, os meristemas foram inoculados, individualmente, em tubos de ensaio $(15 \mathrm{~mm}$ x $150 \mathrm{~mm}$ ) contendo $6 \mathrm{~mL}$ de meio MS semi-sólido acrescido de $1 \mathrm{mg} \mathrm{L}^{-1}$ de 6-benzilaminopurina (BAP), $0,01 \mathrm{mg} \mathrm{L}^{-1}$ de ácido naftalenoacético (ANA), $0,1 \mathrm{mg} \mathrm{L}^{-1}$ de ácido giberélico $\left(\mathrm{AG}_{3}\right), 30 \mathrm{~g} \mathrm{~L}^{-1}$ de sacarose e $7 \mathrm{~g} \mathrm{~L}^{-1}$ de ágar. Após a adição de ágar, o pH do meio de cultura foi ajustado para 5,9. A autoclavagem foi realizada à temperatura de $121^{\circ} \mathrm{C}$ sob $1,5 \mathrm{~atm}$, por 15 minutos. $\mathrm{O}$ cultivo dos meristemas foi feito em sala de cultura com intensidade luminosa de $20 \mu \mathrm{E} \mathrm{m}^{-2} \mathrm{~s}^{-1}, 25 \pm 2^{\circ} \mathrm{C}$ e fotoperíodo de 16 horas.

Após 60 dias, avaliou-se a porcentagem de sobrevivência dos meristemas de ambas as cultivares, os quais foram transferidos para frascos de vidro (120mm de altura $\times 50 \mathrm{~mm}$ de diâmetro) contendo $40 \mathrm{~mL}$ de meio MS com $0,8 \mathrm{mg} \mathrm{L}^{-1}$ de BAP, $30 \mathrm{~g} \mathrm{~L}^{-1}$ de sacarose e $7 \mathrm{~g} \mathrm{~L}^{-1}$ de ágar. $\mathrm{O}$ ajuste do $\mathrm{pH}$, a autoclavagem e as condições de cultivo foram realizados da mesma forma relatada anteriormente. Foram conduzidos três subcultivos de 45 dias (subcultivos 1, 2 e 3) para multiplicação dos explantes.
Explantes de 8-10mm contendo 3-4 gemas de cada cultivar foram avaliados por três subcultivos de 45 dias (subcultivos quatro, cinco e seis), sob condições ambientais de $25 \pm 4^{\circ} \mathrm{C}, 20 \mu \mathrm{E} \mathrm{m}^{-2} \mathrm{~s}^{-1} \mathrm{e}$ fotoperíodo de 16 horas, em meio MS modificado quanto à concentração de $\mathrm{FeSO}_{4} \cdot 7 \mathrm{H}_{2} \mathrm{O}\left(0,25,50 \mathrm{e} 75 \mathrm{mg} \mathrm{L}^{-1}\right)$, acrescido de $0,8 \mathrm{mg} \mathrm{L}^{-1}$ de BAP, $30 \mathrm{~g} \mathrm{~L}^{-1}$ de sacarose e $7 \mathrm{~g}$ $\mathrm{L}^{-1}$ de ágar. $\mathrm{O}$ delineamento utilizado foi inteiramente casualizado, em um bifatorial (duas cultivares x quatro concentrações de ferro), com quatro repetições. A unidade experimental foi constituída por um frasco contendo cinco explantes. As variáveis analisadas foram: taxa de multiplicação (número de brotos produzidos ao final de cada subcultivo por explante inoculado) e comprimento de brotos (mm). Para a determinação do número total de brotos (plantas) produzidos por explante, multiplicaram-se os valores obtidos nos subcultivos quatro, cinco e seis.

Os dados foram submetidos à análise de variância, comparando-se as médias do fator cultivar pelo teste de Tukey $(\mathrm{P}<0,05)$ e do fator concentração de ferro no meio de cultura, por análise de regressão polinomial.

A porcentagem de sobrevivência dos meristemas inoculados foi de $70 \%$ para a cultivar 'Heritage' e de $43 \%$ para a cultivar 'Batum'. Nos três subcultivos iniciais em meio MS completo com $0,8 \mathrm{mg}$ $\mathrm{L}^{-1} \mathrm{BAP}$ (subcultivos um, dois e três), todos os brotos de framboeseira apresentaram sintomas de deficiência de ferro. Isso demonstra que a framboeseira é mais exigente nesse micronutriente do que a maioria das espécies (HANSEN et al., 2006). Nos três subcultivos posteriores $(4,5$ e 6$)$, determinou-se significância da interação entre os fatores cultivar e concentração de ferro no meio de cultivo sobre o número de brotos de framboeseira (Figura 1A, 1B e 1C). Para as duas cultivares estudadas, o efeito da concentração de ferro do meio de cultura sobre o número de brotos produzidos foi ajustado a modelos quadráticos de regressão nos três subcultivos. Na figura 1B e 1C, subcultivos cinco e seis, observa-se desempenho similar das duas cultivares quanto à taxa de multiplicação nas diferentes concentrações de $\mathrm{FeSO}_{4} .7 \mathrm{H}_{2} \mathrm{O}$, embora a 'Heritage' sempre tenha sido mais responsiva in vitro. Apenas no subcultivo quatro os resultados foram distintos (Figura 1A), provavelmente em função da mudança na composição do meio de cultivo. A ausência de ferro no meio ocasionou morte de todos os brotos no subcultivo seguinte, confirmando sua essencialidade.

Com base nos resultados obtidos nos subcultivos quatro, cinco e seis, determinaram-se as concentrações de $\mathrm{FeSO}_{4} \cdot 7 \mathrm{H}_{2} \mathrm{O}$ que otimizam a multiplicação da cv. 'Heritage' (853,3 brotos) e da 'Batum' (523,7 brotos), as quais foram 43,4 e 43,1 $\mathrm{mg} \mathrm{L}^{-1}$, 


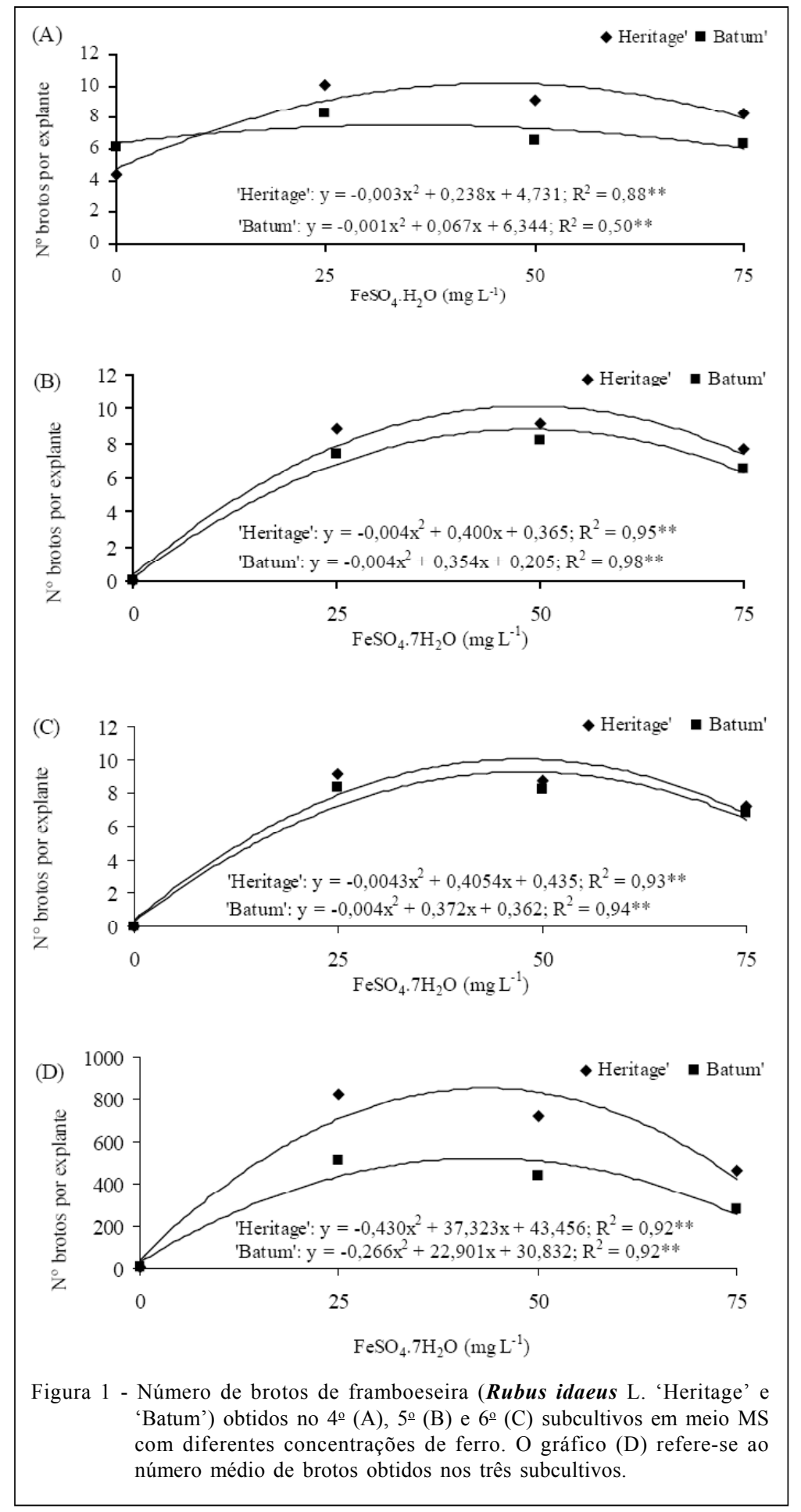

respectivamente (Figura 1). Essas concentrações de ferro são bastante superiores à recomendada por MURASHIGE \& SKOOG (1962) no seu meio MS, que é de $27,85 \mathrm{mg} \mathrm{L}^{-1}$. Os resultados evidenciam a necessidade de suplementação do meio MS com ferro para a micropropagação de framboeseira.
O número médio de brotos foi 6,9 para 'Heritage' e 6,0 para 'Batum', proporcionando, nos três subcultivos, produção de 501,1 e de 306,3 plantas por explante, respectivamente (Figura 1D). O maior potencial de multiplicação da 'Heritage' em relação à 
'Batum' já havia sido demonstrado por OLIVEIRA \& NINO (2009).

Independentemente da cultivar e da concentração de ferro no meio de cultura, o número médio de brotos foi de 6,5 por subcultivo, proporcionando a produção de 403,7 plantas ao final dos três subcultivos estudados. Esse resultado evidencia a facilidade de micropropagação da framboeseira.

Para a variável comprimento de brotos, a significância da interação entre os fatores cultivar e concentração de ferro foi determinada apenas nos subcultivos 4 e 5 (Figura $2 \mathrm{~A}$ e $2 \mathrm{~B}$ ), nos quais o desempenho da 'Heritage' foi superior ao da 'Batum'.

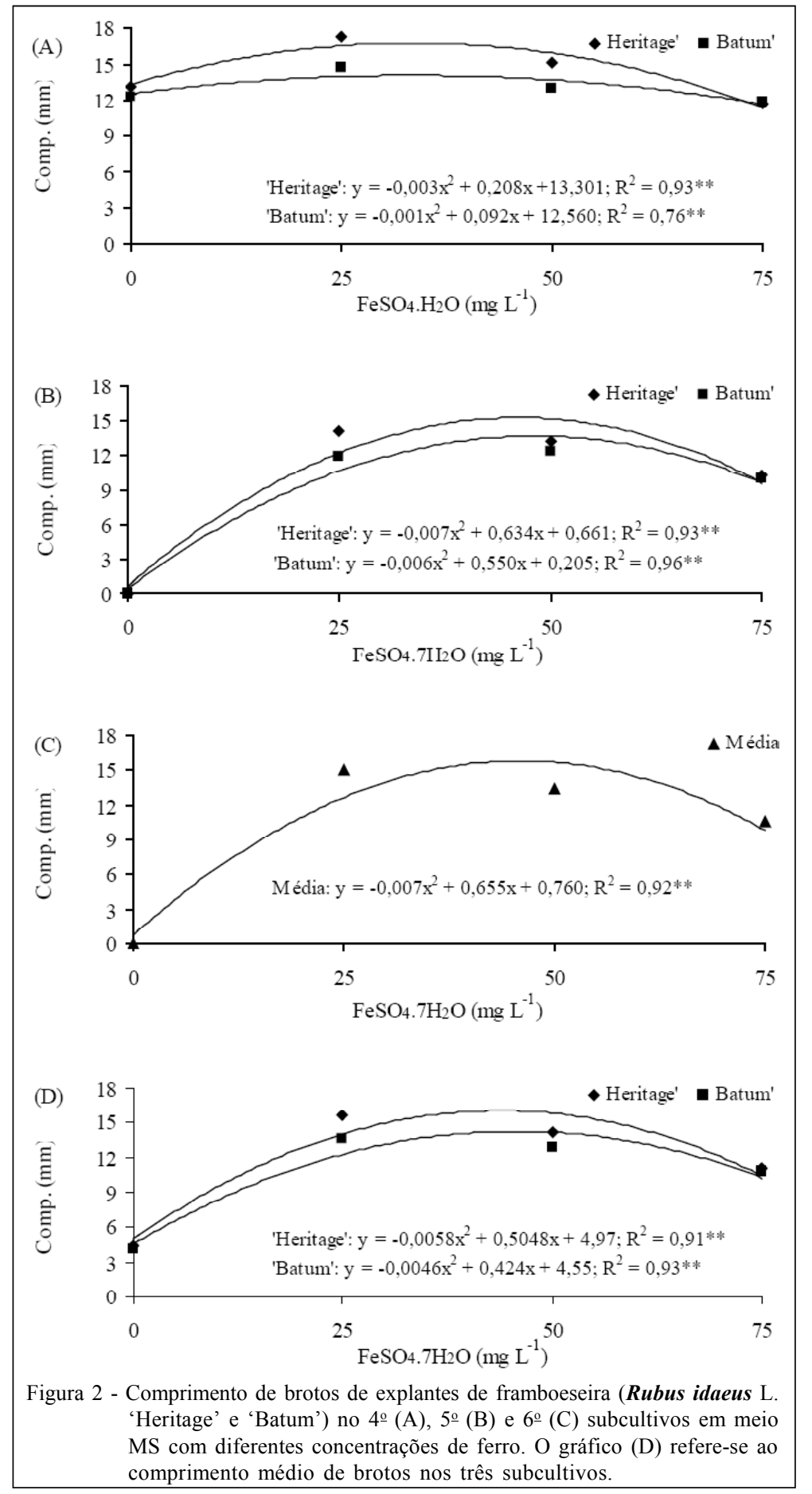

Ciência Rural, v.40, n.12, dez, 2010. 
Para ambas as cultivares, o efeito da concentração de ferro do meio de cultura sobre o comprimento dos brotos desenvolvidos in vitro ajustou-se ao modelo quadrático de regressão. Com base na média dos três subcultivos, determinaram-se 43,5 e $46,1 \mathrm{mg} \mathrm{L}^{-1}$ como sendo as concentrações de $\mathrm{FeSO}_{4} .7 \mathrm{H}_{2} \mathrm{O}$ que otimizam o comprimento médio dos brotos das cultivares 'Heritage' (15,9mm) e 'Batum' (14,3 mm), respectivamente (Figura 2D). Sob concentrações de $\mathrm{FeSO}_{4} \cdot 7 \mathrm{H}_{2} \mathrm{O}$ inferiores a $25 \mathrm{mg} \mathrm{L}^{-1}$ no meio de cultura, os brotos apresentavam-se finos e curvados, concordando com a descrição apresentada por DECHEN \& NACHTIGALL (2006) para deficiência de ferro.

\section{REFERÊNCIAS}

DECHEN, A.R.; NACHTIGALL, G.R. Micronutrientes. In: FERNANDES, M.S. (Ed.). Nutrição mineral de plantas.
Viçosa: Sociedade Brasileira de Ciência do Solo, 2006. p.327354.

HANSEN, N.C. et al. Iron nutrition in field crops. In: BARTON, L.L.; ABADIA, J. (Ed.). Iron nutrition in plants and rhizospheric microorganisms. Dordrecht: Springer, 2006. p.23-59.

IBGE. Framboesa. Sidra. Acesso em: 19 ago. 2010. Online. Disponível em: http://www.sidra.ibge.gov.br.

MURASHIGE, T.; SKOOG, F. A revised medium for rapid growth and bioassays with tobacco tissue cultures. Physiologia Plantarum, v.15, n.3, p.473-497, 1962. Disponível em: $<$ http://onlinelibrary.wiley.com/doi/10.1111/j.13993054.1962.tb08052.x/abstract>. Acesso em: 19 ago. 2010. doi: 10.1111/j.1399-3054.1962.tb08052.x.

OLIVEIRA, R.P.; NINO, A.F.P. Potencial de multiplicação in vitro de cultivares de framboeseira. Revista Brasileira de Fruticultura, v.31, p.280-284, 2009. Disponível em: <http:/ /www.scielo.br/pdf/rbf/v31n1/v31n1a40.pdf>. Acesso em: 19 ago. 2010. doi: 10.1590/S0100-29452009000100040. 